\title{
THE BUILT ENVIRONMENT AND COLLECTIVE EFFICACY
}

\author{
Deborah A Cohen, MD, MPH, Sanae Inagami, MD, MPH, and Brian Finch, PhD
}

\begin{abstract}
Collective efficacy, or perception of mutual trust and willingness to help each other, is a measure of neighborhood social capital and has been associated with positive health outcomes including lower rates of assaults, homicide, premature mortality, and asthma. Collective efficacy is frequently considered a "cause", but we hypothesized that environmental features might be the foundation for, or the etiology of personal reports of neighborhood collective efficacy. We analyzed data from the Los Angeles Family and Neighborhood Study (LA FANS) together with geographical data from Los Angeles County to determine which social and environmental features were associated with personal reports of collective efficacy, including presence of parks, alcohol outlets, elementary schools and fast food outlets. We used multi-level modeling controlling for age, education, annual family income, sex, marital status, employment and race/ethnicity at the individual level. At the tract level we controlled for tract level disadvantage, the number of off-sale alcohol outlets per roadway mile; the number of parks and the number of fast-food outlets within the tract and within one-half mile of the tract's boundaries. We found that parks were independently and positively associated with collective efficacy; alcohol outlets were negatively associated with collective efficacy only when tract level disadvantage was not included in the model. Fast food outlets and elementary schools were not linearly related to collective efficacy. Certain environmental features may set the stage for neighborhood social interactions, thus serving as a foundation for underlying health and well-being. Altering these environmental features may have greater than expected impact on health.
\end{abstract}

\section{Keywords}

Collective efficacy; alcohol outlets; parks; fast food; health disparities; built environment

\section{Introduction}

\begin{abstract}
Where we live determines in part the daily exposures that influence our knowledge, attitudes, and behaviors. Our daily exposures include everything we see, who we meet, and everything we hear, feel or otherwise perceive. These daily exposures are more than just an input, they are also a series of constraints or facilitators that actively play a role in our daily movements, our successes, failures, personal relationships, and individual well-being. People who live in the same area are more alike than those who live in different areas, not only because of the choice they made to live in that area, but because they all have common exposures. Given the likelihood that there is a dynamic relationship between people and their environments, that people act on their environments as well as environments acting on people, understanding the collective influence of neighborhood exposures could enhance our ability to understand the distribution of various health and social outcomes.
\end{abstract}

Corresponding Author: Dr. Deborah A. Cohen, MD, MPH, RAND.

Publisher's Disclaimer: This is a PDF file of an unedited manuscript that has been accepted for publication. As a service to our customers we are providing this early version of the manuscript. The manuscript will undergo copyediting, typesetting, and review of the resulting proof before it is published in its final citable form. Please note that during the production process errors may be discovered which could affect the content, and all legal disclaimers that apply to the journal pertain. 
Problematic health conditions, such as obesity (Robert 2004; Inagami et al. 2006; Allison et al. 2004; Lenthe and Machenbach 2002), sexually transmitted diseases (Cohen et al. 2000), and violence (Sampson et al. 1997; Sampson et al. 2005), affect certain communities and racial/ ethnic groups disproportionately. Many have pointed to the "built environment", (i.e., the way we design and build our communities and neighborhoods), as a source of individual outcomes such as mental health status (Weich et al. 2002; Ellaway and Macintyre 2004; Guite et al. 2006), self-rated health (Cummins et al. 2005), obesity (Ewing et al. 2006; Frank et al. 2004; Lake and Townshend 2006) and health behaviors such as diet (Morland et al. 2002), physical activity, (King et al. 2006; Li et al. 2005; Frank et al. 2005) and risky sex (Cohen et al. 2000). Access to food outlets, parks and recreational facilities, pharmacies, alcohol outlet stores, deteriorated housing and urban design have all been investigated in their links to health (Cohen et al. 2000; Weich et al. 2002; Ellaway and Macintyre 2004; Guite et al. 2006; Cummins et al. 2005; Lake and Townshend 2006; Ewing et al. 2006; King et al. 2006; Li et al. 2005; Frank et al. 2005; Frank et al. 2004; Hill and Peters 1998; Hill et al. 2003; Morrison et al. 2000; Scribner et al. 1998, 1999; Morland et al. 2002; Gordon-Larsen 2006). Many studies have suggested that the unequal distribution of these resources contributes to obesity (Horowitz et al. 2004; Gordon-Larsen 2006), homicide (Scribner et al. 1999) and sexually transmitted diseases (Scribner et al. 1998) in low income, minority populations.

In addition to the built environment, social capital, defined as the ability to secure resources by virtue of membership in social networks, has been examined as a mechanism behind the relationship between neighborhood poverty and ill health (Cattell 2001). Social capital can refer to specific neighborhood ties held by individuals that yield benefits to individuals (Portes and Landolt 2000) but has also been referred to a property possessed by communities, "features of social organization (within communities) such as trust, norms, and networks, that can improve the efficiency of society by facilitating coordinated action" (Portes and Landolt 2000; Putnam 1993). Within the framework of health, the former refers to individuals who derive a health benefit from being more connected to specific neighborhood networks (i.e., strong social support, civic participation) and the latter to health benefits derived from living in communities with richer social interactions (i.e., high collective socialization). Despite the fact that there is broad interpretation and debate as to the "appropriate" construct of social capital (Lochner et al. 1999), various definitions have been associated with health outcomes (Kawachi et al. 1999, 2004; Caughy et al. 2000; Veenstra 2000; Subramanian et al. 2002, 2003; Sampson et al. 1997; Martin et al. 2004; Lochner et al. 2003; Patterson et al. 2004). The diversity and heterogeneity of the different constructs of social capital probably contributes to the difficulty in understanding the magnitude of effect of "social capital" on health outcomes (Lochner 1999; Kawachi et al. 2004).

"Collective efficacy," (Sampson et al. 1997) a form of social capital, is a standardized and well-tested aggregate measure of individual perceptions of "social cohesion among neighbors combined with the willingness to intervene on behalf of the common good". This measure was created in specific contrast to other measures of social capital which were dependent on specific neighborhood networks or on an individual's specific ties to those networks. Lower levels of collective efficacy have been associated with overweight and obesity in children and adolescents (Cohen et al. 2005) and a variety of other outcomes, including mental health (Araya et al. 2006, Xue et al. 2005) higher crime and homicide (Sampson et al. 1997), and allcause mortality and mortality from cardiovascular disease (Cohen et al. 2003; Lochner et al. 2002).

The role of specific neighborhood or area characteristics may be more complex because social and physical dimensions may be interrelated (Diez-Roux 2001). Features of the physical environment may influence not only individual social interactions but also resident perceptions of the social environment (and vice versa) (Diez-Roux 2001). Other studies have shown that 
environmental and social factors are associated with the biological stress response system (Evans and Kantrowitz 2002; Seeman and McEwen 1996; Taylor et al. 1997; McEwen 1998).

"Collective efficacy" is frequently considered a "cause", but we hypothesized that environmental features might be the foundation for, or the etiology of personal reports of neighborhood collective efficacy, independent of the composition of the people who lived in the neighborhoods and their concomitant socio-demographic characteristics.

Collective efficacy is an intangible social construct, based on human resources. In contrast, features of the physical environment are tangible, capital resources. Tangible features of the environment create the settings and context in which people interact with each other; therefore, it is plausible that exposure to their design and appearance would influence these social interactions. For example, in a setting that is bright, clean, with open spaces, we might be more apt to walk outside (Li et al. 2005) and feel friendly or trusting (Altschuler et al. 2004). We might not only interact with others, but we may observe neighbors interacting with other neighbors. In contrast, in a setting that is dark, disordered, and hazardous, we might not only be more cautious, withdrawn (Aneshensel and Sucoff et al. 1996) and unlikely to venture outside (Harrison et al. 2007; Shenassa et al. 2006), but also may not observe our neighbors interacting with others in ways that promote health.

Physiologically, the human brain perceives environmental stimuli and responds automatically. Not all perceptions and responses reach the level of human consciousness. The "chameleon effect" is the name given to the phenomenon that merely perceiving an action results in an increased likelihood that the perceiver will engage in that behavior, regardless of whether we are consciously aware of either the stimulus or the response (Chartrand and Bargh 1999). Another phenomenon, called "stereotype activation" results in automatic responses when faced with images that fit stereotypes, such as a fear reactions to individuals of different racial and ethnic backgrounds, which some people have to learned to suppress (Bargh et al. 1996; Dijksterhuis et al. 2001). The automatic and unconscious response to environmental stimuli may be a mechanism though which a construct like collective efficacy may develop.

Parks, schools, and alcohol and fast food outlets are all features of the built environment that may contribute to the development of, or the undermining of social trust/collective efficacy. Parks were designed as places to relax, experience nature, exercise, socialize, play sports, have picnics and other celebrations (Olmstead 1870). One would expect that parks that evoke positive images might facilitate social interactions and cooperation. Alcohol outlets have been shown to be associated with deviant behaviors, including assaults (Brismar and Bergman 1998; Kelleher et al. 1996; Scribner et al. 1994), homicides (Scribner et al. 1999) sexually transmitted diseases (Scribner et al. 1998) and motor vehicle fatalities (Scribner et al. 1994). Alcohol is a psychoactive drug that facilitates aggression and interferes with motor coordination. The presence of alcohol outlets may thus interfere with development of trust and cooperation. Fast food outlets might negatively affect collective efficacy and the development of interpersonal interactions as they encourage eating high calorie foods on the go, and discourage the slower, more considered meal preparation and meal times where people not only eat together, but converse with each other about their lives and feelings (Putnam 2000). Greater numbers of elementary schools may enhance collective efficacy as parents congregate and interact with other parents as they deliver their children to school.

In order to test each of these hypotheses, we analyzed data collected from the Los Angeles Family and Neighborhood Survey (LAFANS). 


\section{DATA AND METHODS}

We selected the Los Angeles Family and Neighborhood Survey (LAFANS) to conduct our analyses of the structural predictors of collective efficacy. The first wave of the LAFANS survey was carried out between the Spring of 2000 and the end of 2001 among 65 neighborhoods (using 2000 Census data, aggregated by 1990 census tract boundaries) in Los Angeles County. Although the sample contains neighborhoods across the income range, the sample-design purposefully over-sampled poor (between the $60^{\text {th }}-89^{\text {th }}$ percentile of the poverty distribution) and very poor (top decile) neighborhoods. LAFANS was designed specifically as a multilevel survey, sampling census tracts first, then families within the tracts, and then children within these families. United States census tract boundaries normally follow visible features, but may follow governmental unit boundaries and other non-visible features. They are designed to be relatively homogeneous units with respect to population characteristics, economic status, and living conditions, and average about 4,000 inhabitants (http://ask.census.gov/). The two census tracts eliminated from our sample were anomalous, about five times larger than the largest of the other census tracts, comprising areas larger than 126,000 acres and roadway miles greater than 350 miles.

Within census tracts our analytical sample consists of 2,431 adult respondents with valid responses to a collective efficacy scale and income information of the entire set of 2,620 adult respondents interviewed. We eliminated 54 respondents who were missing responses to the collective efficacy scale, and 26 who were missing income information. We also eliminated 23 respondents who were employed and yet reported " 0 " income and 88 respondents from two very large census tracts. Details regarding both the sampling frame and LAFANS data are available elsewhere (Sastry et al. 2003).

Non-response rates in LAFANS are relatively low and match those of other major surveys (Sastry and Pebley 2003); among eligible English- or Spanish- speaking households, the refusal rate was $16 \%$. More importantly, thorough multivariate analyses of these patterns conclude, "non-response is not a major problem in LAFANS" (Sastry and Pebley 2003, p. 15).

\section{Collective Efficacy}

Our key outcome measure of collective efficacy is based on items collected in previous research by Sampson, Raudenbush, and Earls (1997), and reflects a combination of factors related to individual perception of social cohesion (five items) and informal social control in a neighborhood (three items), detailed in Table 1 . These items factor together vary cohesively, as indicated by the Cronbach's alpha of .77 across all items. Traditionally, collective efficacy is used as an aggregate measure of the neighborhood, but our analysis focused on the neighborhood features that influence individual ratings of collective efficacy.

\section{Neighborhood/Tract Level Disavantage}

Four summary statistics of census tracts in Los Angeles County were each standardized and then combined to measure socio-economic status (SES) and create a neighborhood "socioeconomic score": (1) percent living below the poverty line, (2) percent of households that are headed by a female, (3) percent male unemployment, and (4) percent of families receiving public assistance.(Sampson et al. 1997) The tract level disadvantage measure was analyzed as a continuous variable in our regression analyses where lower scores were associated with more disadvantaged neighborhoods (reverse coded).

\section{Characteristics of the Built Environment}

Based on what we understand about the built environment and relationships with health and well-being, we considered socio-demographic characteristics of a tract, as well as 
characteristics of the built environment. We examined population density, neighborhood socioeconomic status, the distribution and diversity of land-use based on zoning boundaries, multiple measures of street connectivity, in addition to the number and concentration of alcohol outlets, the number and acreage of parks within various distances of ones tract of residence, the number and concentration of fast food outlets, and the number of schools. The number of alcohol outlets (and fast food restaurants) were divided by roadway miles to estimate an effective density measure for those variables. We also calculated boundaries at 1/4 mile, $1 / 2$ mile and 1 mile beyond the census tract and counted parks, fast food outlets and schools in these areas, since people who live at the edge of the tract are likely to be exposed to the contiguous neighborhoods, which may be closer than other within tract areas. The number of parks and liquor stores were analyzed as continuous measure. The characteristics of these distributions are present in Table 2.

\section{Individual-Level Covariates}

In order to control for the compositional characteristics of tracts, we include a number of individual-level covariates in our statistical models. These include log age in years, college education (reference $=$ no college education), $\log$ annual family income, female sex (reference=male), marital status (reference $=$ unmarried $),$ employment $($ reference $=$ unemployed $)$ and race/ethnicity (Latino, African-American (reference=white+other)). Age and income were logged to normalize its skewed distribution. The characteristics of these distributions are presented in Table 2.

\section{Statistical Model}

We estimate a simple hierarchical linear model (HLM) with a random-intercept that allows for the incorporation of both individual-level (x) and tract-level characteristics (z). This model adjusts for a heteroscedastic dependence of $\mathrm{x}$ on the level-two error term and contains error terms at both level-one (individual-level characteristics) and level-two (tract). The randomintercept models estimated here control for the non-independence of cases within census tracts, but not for any dependence across contiguous or nearby census tracts.

$$
Y_{i j}=\gamma_{00}+\sum_{h=1}^{p} \gamma_{h 0} x_{h i j}+\sum^{q} \gamma_{0 k} z_{k j}+\sum_{k=1}^{q} \sum_{h=1}^{p} \gamma_{h k} z_{k j} x_{h i j}+U_{0 j}+\sum_{h=1}^{p} U_{h j} x_{h i j}+R_{i j}
$$

This model estimates expected change in individual level collective efficacy for an additional unit of change in predictors and covariates $\left(\gamma_{h}\right)$ for various values of $x$ for the ith person in the $j^{\text {th }}$ census tract (Snijders and Bosker 1999). Neighborhood level predictors are considered values of $\mathrm{z}$ for the $j^{\text {th }}$ group and can be used to explain either average efficacy across tracts or variation in slopes across tracts (i.e. cross-level interactions). We are largely interested in the main effects of structural characteristics and thus, tract characteristics are used to explain mean differences across tracts. Again, all residents of the same tract receive the same value for the tract-level variables and are considered spatially dependent, an attractive feature of the HLM. We specify the following models: 1) a null model that partitions the variance to within- and between- tract components; 2) a model that includes individual-level characteristics only, and 3) a full model which includes neighborhood measures of parks within the census tract and within one-half mile boundaries.

\section{Weights}

The study used a multistage stratified sample design in which tracts, blocks within tracts and households were sampled. Tracts were stratified by the percentage of the population in the tract 
who were in poverty and by whether household included children under age 18 . Weights adjusted for unequal probabilities of sample selection and household non-response.

\section{RESULTS}

Table 1 lists the items that were used to compute collective efficacy at the tract level. The reliability of our collective efficacy scale was 0.77 . Our sample includes a population that is 58\% Latino, 24\% Non Hispanic White, and 8\% African American. The average number of parks within a census tract and within $1 / 4,1 / 2$ and 1 mile boundaries was $1.4,2.8,4.9$, and 10.5 respectively.. For fast food outlets it was respectively 1.4, 5.1, 9.7, and 21.6. There was an average of 0.8 liquor stores/roadway mile within any boundary drawn around the census tract up to one mile (Table 2). Average roadway miles/census tract was 17.8 with a range between 6 and 79 miles.

Table 3 compares the structural features among neighborhoods high in collective efficacy and low in efficacy. High efficacy tracts tend towards concentrated affluence, with more parks, and fewer alcohol outlets; there were no association seen between the number of fast food outlets nor the number of elementary schools and collective efficacy.

The hierarchical models are presented in Table 4. Model A partitions the variance to both within- and between- tract components and allows us to estimate an intra-class correlation coefficient (ICC). The results indicate that $19.5 \%$ of the variation in collective efficacy in our sample is due to characteristics that vary between tracts. These characteristics may be due to differential composition of the tracts (i.e., different people live in different tracts) or may be due to contextual characteristics of the tracts themselves. Our next two models attempt to capture both what explains this overall variation and to determine what particular characteristics of both persons and tracts predict collective efficacy. Model B includes relevant individual-level covariates and explains none of the between-tract variance. Latino ethnicity is positively related to collective efficacy. The remaining individual-level variables are statistically non-significant and unrelated to collective efficacy, though marital status almost reached statistical significance.

Model C, adds tract level disadvantage, and with the addition of the individual-level characteristics, explains about $51 \%$ of the original between-tract variance. Our ICC is reduced to almost $11 \%$, suggesting that a large proportion of the tract-level variance in collective efficacy has been explained by tract level disadvantage. Model D adds tract level parks to the model and explains another $0.5 \%$ of the original between-tract variance. Model E which includes number of parks within a $1 / 2$ mile boundary, instead of only the number of parks within the tract, explains more of the original between tract variance. Both the number of parks and neighborhood disadvantage are statistically significant $(\mathrm{p}<0.001)$ predictors of collective efficacy. The results of neighborhood disadvantage indicates that with greater community affluence, collective efficacy increases. Living in a neighborhood with more parks is strongly associated with higher levels of reported efficacy. A higher density of off-sale liquor outlets in one's neighborhood (residential census tract within a $1 / 4$ mile boundary) is negatively and marginally associated with collective efficacy when included alone in the model without neighborhood disadvantage $(\beta=-0.241, \mathrm{p}=0.003$; data not shown in Table 3.), but when included with neighborhood disadvantage becomes statistically insignificant $(\beta=0.007$, $\mathrm{p}=0.921$ ), most likely due to high collinearity.

The number of fast food establishments and number of elementary schools were not linearly associated with levels of collective efficacy.

These effects are relatively easy to interpret within the context of a linear model. Beta coefficients represent the effect of a full one-unit increase in predictor variables on the predicted 
collective efficacy scores. However, given that the predictor variables are operationalized in various metrics, we will present the interpretation of the significant tract-level variables for increases at two standard deviations from the mean of the distribution. As such, a two-standard deviation increase in the tract-level disadvantage would result in a .44 unit predicted increase in collective efficacy ratings (which is more than half of a standard deviation in collective efficacy). Based upon studies linking collective efficacy to health outcomes in Chicago, we estimated that this increase in collective efficacy would be associated with the following health outcomes: a reduction of 74 premature deaths, 60 cardiovascular deaths, 104 homicides, and 11 malignant neoplasms (Cohen et al. 2003). This same effect of tract disadvantage would translate to a $48 \%$ reduction in the probability of asthma/breathing problems among adult residents of Chicago neighborhoods (Cagney and Browning 2004). Finally, the indirect effect of a two standard deviation increase of tract disadvantage on collective efficacy is associated with the following risks for crime in Chicago: .28 fewer violent crimes per neighborhood, .55 fewer victimizations per neighborhood, and .52 fewer homicides per neighborhood (Sampson et al 1997). The estimated effects for homicide between the Sampson 1997 study differs from that by Cohen and colleagues, largely due to a difference in control variables - the estimated effect derived from the Cohen study (104 homicides) is Chicago-wide, while the effect in the Sampson study is 0.52 per Chicago neighborhood $(n=343)$, for a total of 178 homicides.

A two standard deviation increase in the number of parks per census tract would result in a marginal 0.14 unit decrease in collective efficacy rating, a relatively small effect on the predicted rating of self-efficacy. Again, if this effect were in Chicago, it would translate to 21 fewer premature deaths, 17 fewer cardiovascular deaths, 31 fewer homicides, 3 fewer malignant neoplasms, a $14 \%$ reduction in the probability of asthma/breathing problems, 0.08 fewer violent crimes per neighborhood, 0.16 fewer victimizations per neighborhood, and 0.16 fewer homicides per neighborhood.

\section{DISCUSSION AND CONCLUSIONS}

This study demonstrates an association between fixed physical features of neighborhoods, parks and alcohol outlets and personal rating of collective efficacy, a social construct, controlling for individual demographic characteristics and residential neighborhood socioeconomic status. Parks are considered community assets and do bring people in the surrounding areas to a common place for leisure purposes, a time when people are more likely to be open to what they see around them and receptive to others, because they are recreating together and sharing a common space. Although we did not specifically assess the condition of these parks in Los Angeles, they usually have a full-time staff and the parks tend to be wellmaintained, and there are frequent police patrols through parks in neighborhoods with higher rates of crime (Cohen et al. 2007). If parks were in poor condition and considered dangerous places where drug or gang activities occur, they may have had an opposite association with collective efficacy. The association seen between collective efficacy and parks continues to be present at the level of the census tract and at $1 / 4$ and $1 / 2$ mile boundaries. Parks within a $1 / 2$ mile boundary explains a greater proportion of the original between tract variance $(7 \%)$ than parks within the census tract (4\%) probably because respondents in a particular census tract may be more likely to live closer to parks in contiguous tracts rather than in their own tract, which may be 1-3 square miles. People are more likely to visit areas that are in closer proximity to their homes, regardless of the census tract (Cohen et al, 2007).

Pedestrian-oriented, mixed use neighborhoods have been shown to be associated with increased familiarity with neighbors and greater social engagement (Leyden 2003). Previous studies examining spatial features of neighborhoods, such as sprawl and population density have found increased civic engagement in very high density neighborhoods, and reduced civic engagement in sprawling neighborhoods and among people who have long commuting times 
(Williamson, 2002; Putnam, 2000). Our study differs from these in that we examined very specific land use categories and their association with collective efficacy, which does not include measures of voting or political participation.

Alcohol outlet store density (alcohol outlet numbers/block group) has been associated with a resident's perception of neighborhood social and physical disorder (Sampson and Raudenbush 2004). Off-sale alcohol outlets are places where people come and go, and are often sites for loitering and public drinking. Because alcohol is associated with the release of inhibitions in our culture, alcohol outlets may promote loose and uncontrolled behaviors. Excessive drinking alters one's perceptions and appreciation of the world around them. Drunkenness is associated with behaviors that are considered dangerous, unpredictable and unstable, so it may be no surprise that alcohol outlets do not appear to promote trusting, friendly and helpful relationships. In our study, increased alcohol outlet store density showed an association with lower levels of collective efficacy, but because density of off-sale alcohol outlets is highly correlated with tract disadvantage, the independent association of alcohol outlets to collective efficacy could not be teased out in the hierarchical model.

The lack of linear association with schools and fast food outlets with collective efficacy may be related to the varying dynamics of their use. Schools may be positively associated with collective efficacy up until a certain threshold. If there are many schools that require bussing of students and long commutes, the chance for increased collective efficacy through building relationship in frequent meetings in local neighborhoods may be diminished. Similarly fast food outlets may be used both by locals and by commuters, so the net effect of improving relationships when locals see each other may be cancelled by having more outsiders in the area.

Social, environmental, and biological factors may not only be associated with each other, but also may interact with each other over the life course to affect health. Our study suggests that there is an association between features of the environment and perceptions of neighborhood social functioning that may indirectly influence health outcomes. Therefore, changes in urban design may determine health and well-being. Longitudinal studies examining changes in urban design and its effects on neighborhood social structure and health are needed.

\section{Acknowledgments}

For provision of fast food outlet data, we wish to thank Los Angeles County Department of Public Health, Environmental Health; Terrance Powell, Interim Director and Michael Doom, Environmental Health Specialist IV, Management Information Systems. This study was supported in part by NIAAA R01AA013749.

\section{References}

Allison A, Hedley, Ogden CL, Johnson CL, Carroll MD, Curtin LR, Flegal KM. Prevalence of Overweight and Obesity Among US Children, Adolescents, and Adults, 1999-2002. Journal of American Medical Association 2004;291:2847-2850.

Altschuler A, Somkin CP, Adler NE. Local services and amenities, neighborhood social capital, and health. Social Science \& Medicine 2004;59(6):1219-29. [PubMed: 15210093]

Aneshensel CS, Sucoff CA. The neighborhood context of adolescent mental health. Journal of Health \& Social Behavior 1996;37(4):293-310. [PubMed: 8997886]

Araya R, Dunstan F, Playle R, Thomas H, Palmer S, Lewis G. Perceptions of social capital and the built environment and mental health. Social Science \& Medicine 2006;62(12):3072-83. [PubMed: 16439045]

Bargh JA, Chen M, Burrows L. Automaticity of social behavior: direct effects of trait construct and stereotype activation on action. Journal of Personality and Social Psychology 1996;71:230-244.

[PubMed: 8765481] 
Brismar B, Bergman B. The significance of alcohol for violence and accidents. Alcoholism: Clinical and Experimental Research 1998;22(7):299S-306S.

Cagney KA, Browning CR. Exploring neighborhood-level variation in asthma and other respiratory diseases: the contribution of neighborhood social context. Journal of General Internal Medicine 2004;19(3):229-236. [PubMed: 15009777]

Cattell, Vicky. Poor people, poor places, and poor health: the mediating role of social networks and social capital. Social Science \& Medicine 2001;52:1501-1516. [PubMed: 11314847]

Caughy MO, O'Campo PJ, Muntaner C. When being alone might be better: neighborhood poverty, social capital, and child mental health. Social Science \& Medicine 2000;57:227-237. [PubMed: 12765704]

Chartrand TL, Bargh JA. The chameleon effect: The perception-behavior link and social interaction. Journal of Personality and Social Psychology 1999;76:893-910. [PubMed: 10402679]

Cohen D, Spear S, Scribner R, Kissinger P, Mason K, Wildgen J. "Broken windows" and the risk of gonorrhea. Am J Public Health 2000;90(2):230-6. [PubMed: 10667184]

Cohen DA, Farley TA, Mason K. Why is poverty unhealthy? Social and physical mediators. Social Science \& Medicine 2003;57(9):1631-1641. [PubMed: 12948572]

Cohen D, Finch B, Bower A, Sastry N. Collective Efficacy and Obesity: The Potential Influence of Social Factors on Health. Social Science \& Medicine. 2005in press

Cohen DA, McKenzie TL, Sehgal A, Williamson S, Golinelli D, Lurie N. Contribution of public parks to physical activity. Am J Public Health 2007;97(3):509-514. [PubMed: 17267728]

Cummins S, Stafford M, Macintyre S, Marmot M, Ellaway A. Neighbourhood environment and its association with self rated health: evidence from Scotland and England. J Epidemiol Community Health 2005;59(3):207-13. [PubMed: 15709080]

Cunradi CB, Caetano R, Clark C, Schafer J. Neighborhood poverty as a predictor of intimate partner violence among White, Black, and Hispanic couples in the United States: a multilevel analysis. Annals of Epidemiology 2000;10(5):297-308. [PubMed: 10942878]

Diez-Roux AV. Investigating neighborhood and area effects on health. American Journal of Public Health 2001;91:1783-1789. [PubMed: 11684601]

Dijksterhuis AU, Spears R, Lépinasse VE. Reflecting and deflecting stereotypes: Assimilation and contrast in impression formation and automatic behavior. Journal of Experimental Social Psychology 2001;37(4):286-299.

Ellaway A, Macintyre S. You are where you live. Evidence shows that where we live has a significant impact on our mental health. Mental Health Today 2004:33-5. [PubMed: 15575587]

Evans GW, Kantrowitz E. Socioeconomic status and health: the potential role of environmental risk exposure. Annual Review of Public Health 2002;23:303-331.

Ewing R, Brownson RC, Berrigan D. Relationship between urban sprawl and weight of United States youth. American Journal of Preventive Medicine 2006;31(6):464-74. [PubMed: 17169708]

Frank LD, Andresen MA, Schmid TL. Obesity relationships with community design, physical activity, and time spent in cars. American Journal of Preventive Medicine 2004;27(2):87-96. [PubMed: 15261894]

Frank LD, Schmid TL, Sallis JF, Chapman J, Saelens BE. Linking objectively measured physical activity with objectively measured urban form: findings from SMARTRAQ. American Journal of Preventive Medicine 2005;28(2S2):117-125. [PubMed: 15694519]

Gordon-Larsen P, Nelson MC, Page P, Popkin BM. Inequality in the Built Environment Underlies Key Health Disparities in Physical Activity and Obesity. Pediatrics 2006;117:417-424. [PubMed: 16452361]

Guite HF, Clark C, Ackrill G. The impact of the physical and urban environment on mental well-being. Public Health 2006;120(12):1117-1126. [PubMed: 17097120]

Harrison RA, Gemmell I, Heller RF. The population effect of crime and neighbourhood on physical activity: an analysis of 15,461 adults. Journal of Epidemiology and Community Health 2007;61(1): 34-9. [PubMed: 17183012]

Hill JO, Peters JC. Environmental contributions to the obesity epidemic. Science 1998;280(5368):13711374. [PubMed: 9603719] 
Hill JO, Wyatt HR, Reed GW, Peters JC. Obesity and the environment: where do we go from here? Science 2003;299(5608):853-855. [PubMed: 12574618]

Horowitz CA, Colson KA, Hebert PL, Lancaster K. Barriers to Buying Healthy Foods for People With Diabetes: Evidence of Environmental Disparities. American Journal of Public Health 2004;94(9): 1549-1554. [PubMed: 15333313]

Inagami S, Cohen DA, Finch BK, Asch SM. You are where you shop: grocery store locations, weight, and neighborhoods. American Journal of Preventive Medicine 2006;31(1):10-17. [PubMed: 16777537]

Kawachi I, Kennedy BP, Glass R. Social capital and self-rated health: a contextual analysis. American Journal of Public Health 1999;89:1187-1192. [PubMed: 10432904]

Kawachi I, Kim D, Coutts A, Subramanian SV. Commentary: Reconciling the three accounts of social Capital. International Journal of Epidemiology 2004;33:682-690. [PubMed: 15282222]

Kelleher KJ, Pope SK, Kirby RS, Rickert VI. Alcohol availability and motor vehicle fatalities. Journal of Adolescent Health 1996;21(2):325-330. [PubMed: 8934292]

King WC, Belle SJ, Brach JS, Simkin-Silverman LR, Soska T, Kriska AM. Objective Measures of Neighborhood Environment and Physical Activity in Older Women. American Journal of Preventive Medicine 2005;28:461-469. [PubMed: 15894150]

Lake A, Townshend T. Obesogenic environments: exploring the built and food environments. Journal of the Royal Society of Health 2006;126(6):262-7.

Lenthe FJ, Mackenbach JP. Neighbourhood deprivation and overweight: the GLOBE study. International Journal of Obesity 2002;26:234-240. [PubMed: 11850756]

Leyden KM. Social capital and the built environment: the importance of walkable neighborhoods. American Journal of Public Health 2003;93(9):1546-51. [PubMed: 12948978]

Li F, Fisher KJ, Brownson RC, Bosworth M. Multilevel modelling of built environment characteristics related to neighbourhood walking activity in older adults. Journal of Epidemiology and Community Health 2005;59:558-564. [PubMed: 15965138]

Lin SJ. Access to community pharmacies by the elderly in Illinois: a geographic information systems analysis. Journal Medical Systems 2004;28(3):301-9.

Lochner K, Kawachi I, Kennedy BP. Social capital: a guide to its measurement. Health and Place 1999;5:259-270. [PubMed: 10984580]

Lochner KA, Kawachi I, Brennan RT. Social capital and neighborhood mortality rates in Chicago. Social Science \& Medicine 2002;56(8):1797-1805. [PubMed: 12639596]

Lochner K, Kawachi I, Brennan RT, Buka SL. Social capital and neighborhood mortality rates in Chicago. Social Science \& Medicine 2003;56:1797-1805. [PubMed: 12639596]

Martin KS, Rogers BL, Cook JT, Joseph HM. Social capital is associated with decreased risk of hunger. Social Science \& Medicine 2004;58:2645-2654. [PubMed: 15081212]

McEwen BS. Preotective and damaging effects of stress mediators. New England Journal of Medicine 1998;338:171-179. [PubMed: 9428819]

Morland K, Wing S, Diez-Roux A. The contextual effect of the local food environment on residents diets: the atherosclerosis risk in communities study. American Journal of Public Health 2002;92:17611767. [PubMed: 12406805]

Morrison RS, Wallenstein S, Natale DK, Senzel RS, Huang LL. "We don't carry that"--failure of pharmacies in predominantly nonwhite neighborhoods to stock opioid analgesics. New England Journal of Medicine 2000;342(14):1023-6. [PubMed: 10749965]

Olmstead, F. Public Parks and the Enlargement of Towns. In: LeGates, RSF., editor. The City Reader. London: Routledge; 1870. p. 314-320.

Patterson JM, Eberly LE, Ding Y, Hargreaves M. Associations of smoking prevalence with individual and area level social cohesion. Journal of Epidemiology and Community Health 2004;58:692-697. [PubMed: 15252073]

Portes A, Landolt P. Social capital: promises and pitfalls of its role in development. Journal of Latin American Studies 2000;32:529-547.

Putnam, R.; Leonardi, R.; Nanatti, R. Making democracy work: civic traditions in modern Italy. Princeton NJ: Princeton University Press; 1993. 
Putnam, R. Bowling Alone: The Collapse and Revival of American Community. New York: Simon and Schuster; 2000.

Robert SA, Reither EN. A multilevel analysis of race, community disadvantage, and body mass index among adults in the US. Social Science \& Medicine 2004;59:2421-2434. [PubMed: 15474198]

Ross CE, Mirowsky J. Neighborhood disadvantage, disorder, and health. Journal of Health and Social Behavior 2001;42(3):258-76. [PubMed: 11668773]

Sampson RJ, Raudenbush SW, Earls F. Neighborhoods and violent crime: a multilevel study of collective efficacy. Science 1997;277(5328):918-24. [PubMed: 9252316]

Sampson RJ, Raudenbush SW. Seeing disorder: Neighborhood stigma and the social construction of “broken windows". Social Psychology Quarterly 2004;67(4):319-342.

Sampson RJ, Morenoff JD, Raudenbush S. Social anatomy of racial and ethnic disparities in violence. American Journal of Public Health 2005;95(2):224-32. [PubMed: 15671454]Erratum in: Am J Public Health. 2006 Apr, 96(4), p. 591

Sastry, N.; Ghosh-Dastidar, B.; Adams, J.; Pebley, AR. The design of a multilevel longitudinal study of children, families and communities: the Los Angeles Family and Neighborhood Study. RAND Labor and Population Working Paper DRU-2400/1-LAFANS; 2003.

Sastry, N.; Pebley, AR. Non-Response in the Los Angeles Family and Neighborhood Survey. RAND Working Paper DRU-2400/7-LAFANS; 2003.

Scribner RA, MacKinnon DP, Dwyer JH. Alcohol outlet density and motor vehicle crashes in Los Angeles County cities. Journal of Studies on Alcohol 1994;55:447-453. [PubMed: 7934052]

Scribner R, Cohen D, Farley T. Geographic relation between alcohol availability and gonorrhea rates. Sexually Transmitted Disease 1998;25(10):544-548.

Scribner R, Cohen D, Kaplan S, Allen S. Alcohol availability and homicide in New Orleans: conceptual considerations or small area analysis of alcohol availability and related outcomes. Journal of Studies on Alcohol 1999;60:310-316. [PubMed: 10371257]

Seeman TE, McEwen BS. Impact of social environment characteristics on neuroendocrine regulation. Psychosomatic Medicine 1996;58:459-471. [PubMed: 8902897]

Shenassa ED, Liebhaber A, Ezeamama A. Perceived safety of area of residence and exercise: a panEuropean study. American Journal of Epidemiology 2006;163(11):1012-7. [PubMed: 16571742]

Snijders, TAB.; Bosker, RJ. Multilevel analysis: an introduction to basic and advanced multilevel modeling. London: Sage Publications; 1999.

Subramanian SV, Kim DJ, Kawachi I. Social trust and self-rated health in US communities: a multilevel analysis. Journal of Urban Health 2002;79(4):S21-S34. [PubMed: 12473696]

Subramanian SV, Lochner KA, Kawachi I. Neighborhood differences in social capital: a compositional artifact or a contextual construct? Health and Place 2003;9:33-44. [PubMed: 12609471]

Taylor SE, Repetti RL, Seeman T. Health psychology: what is an unhealthy environment and how does it get under the skin. Annual Rev Psychology 1997;48:411-447.

Veenstra G. Social capital, SES and health: an individual-level analysis. Social Science \& Medicine 2000;50:619-629. [PubMed: 10658843]

Weich S, Blanchard M, Prince M, Burton E, Erens B, Sproston K. Mental health and the built environment: cross-sectional survey of individual and contextual risk factors for depression. British Journal of Psychiatry 2002;180:428-33. [PubMed: 11983640]

Williamson T. Sprawl, politics, and participation, a preliminary analysis. National Civic Review 2002;91 (3):235-244.

Xue Y, Leventhal T, Brooks-Gunn J, Earls FJ. Neighborhood residence and mental health problems of 5- to 11-year-olds. Archives of General Psychiatry 2005;62(5):554-63. [PubMed: 15867109] 
Table 1

Components of Collective Efficacy Measure.

\begin{tabular}{llll}
\hline Item & Mean & S.D. & Range \\
\hline Social Cohesion Items & & & \\
This is a close-knit neighborhood & 3.15 & 1.14 & $1-5$ \\
People generally don't get along & 3.56 & 0.97 & $1-5$ \\
People are willing to help neighbors & 3.66 & 0.94 & $1-5$ \\
People do not share same values ${ }^{*}$ & 3.09 & 1.05 & $1-5$ \\
People can be trusted & 3.4 & 1.03 & $1-5$ \\
Informal Social Control Items & & & $1-5$ \\
Neighbors do something if kids hang out & 3.45 & 1.31 & $1-5$ \\
Would do something if kid does graffiti & 3.87 & 1.26 & $1-5$ \\
Would scold kid if showing disrespect & 3.35 & 1.25 & $1.15-5.00$ \\
& 3.45 & 0.70 & \\
\hline Collective Efficacy Scale & & & \\
\hline
\end{tabular}

1: Strongly disagree 5 : Strongly agree

*: Reverse coded 
Descriptive Statistics.

\section{Table 2}

\section{Individual-level variables}

Mean Age (SD)

$39.6(14.4)$

Median Annual Family Income

26,200

$\%$ Female

$\%$ Married

$\%$ College Educated

$\%$ Employed

Race/Ethnicity

$\%$ Latino

$\%$ NH Black

$\%$ NH White

$\%$ NH Asian

$\%$ NH Other

\begin{tabular}{llrrr}
\hline Tract -level variables & N & Mean & SD & Range \\
\hline Collective Efficacy & 63 & 3.44 & 0.69 & $1.15-5$ \\
Tract Disadvantage & 63 & -1.36 & 3.48 & $-9.8-4.1$ \\
Off-Sale Alcohol outlets/roadway mile & 63 & 0.8 & 0.6 & $0.06-2.5$ \\
Off-Sale Alcohol outlets/roadway mile (1/4 mile radius) & 63 & 0.8 & 0.5 & $0.06-2.6$ \\
Off-sale Alcohol outlets/roadway mile (1/2 mile radius) & 63 & 0.7 & 0.5 & $0.1-2.3$ \\
Off-sale Alcohol outlets/roadway mile (1 mile radius) & 63 & 0.7 & 0.5 & $0.03-2.6$ \\
Parks in Census Tract & 63 & 1.4 & 1.75 & $0-9$ \\
Parks in Census Tract (1/4 mile radius) & 63 & 2.8 & 2.2 & $0-13$ \\
Parks in Census Tract (1/2 mile radius) & 63 & 4.9 & 10.5 & 5.0 \\
Parks in Census Tract (1 mile radius) & 63 & & 5.0 & $2-32$ \\
& & & \\
\hline
\end{tabular}


Table 3

Characteristics of Tracts with Low and High Levels of Collective Efficacy.

\begin{tabular}{|c|c|c|c|}
\hline & High Collective Efficacy & Middle Collective Efficacy & Low Collective Efficacy \\
\hline Tract Disadvantage & .45 & -1.44 & -3.27 \\
\hline $\begin{array}{l}\text { Off-Sale Alcohol outlets ( } 1 / 4 \\
\text { mile radius) }\end{array}$ & 27.7 & 33.7 & 37.8 \\
\hline $\begin{array}{l}\text { Off-Sale Alcohol outlets/ } \\
\text { roadway mile ( } 1 / 4 \text { mile radius) }\end{array}$ & 0.62 & 0.78 & 0.90 \\
\hline $\begin{array}{l}\text { Number of Parks (1/4 mile } \\
\text { radius) }\end{array}$ & 3.4 & 2.77 & 2.15 \\
\hline $\begin{array}{l}\text { Fast Food Outlets (1/4 mile } \\
\text { radius) }\end{array}$ & 5.2 & 5.0 & 4.76 \\
\hline $\begin{array}{l}\text { Number of Schools ( } 1 / 4 \text { mile } \\
\text { radius) }\end{array}$ & 2.0 & 2.12 & 2.16 \\
\hline
\end{tabular}

Note: High collective efficacy is defined as a respondent living in a neighborhood with efficacy scores that are larger than one standard deviation above the mean while low efficacy neighborhoods are defined as one standard deviation below the mean. Middle collective efficacy is defined as a respondent living in a neighborhood within one standard deviation of the mean. As such, the characteristics of neighborhoods at the average are represented by the descriptive characteristics in Table 2. 


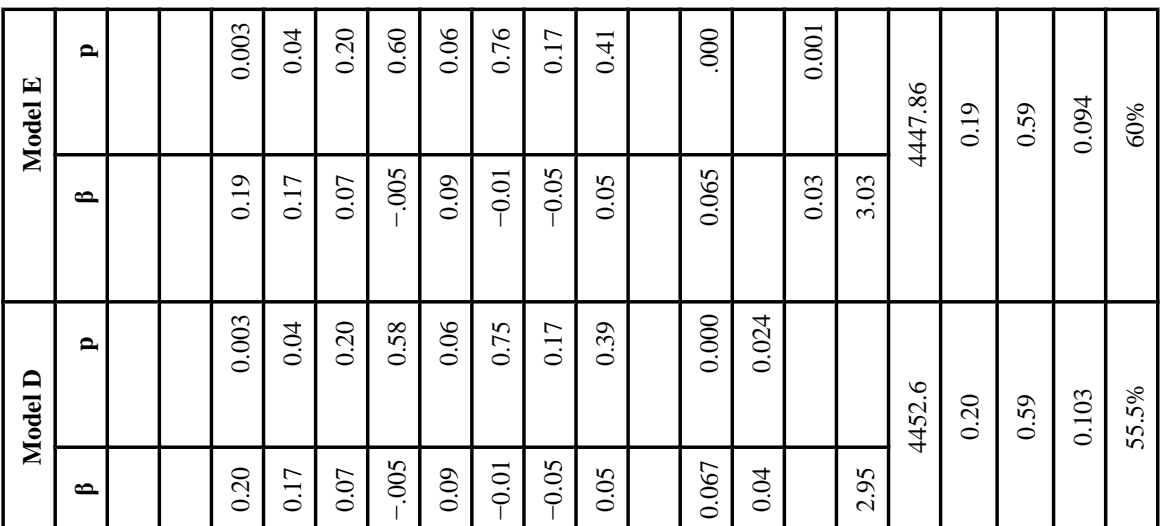

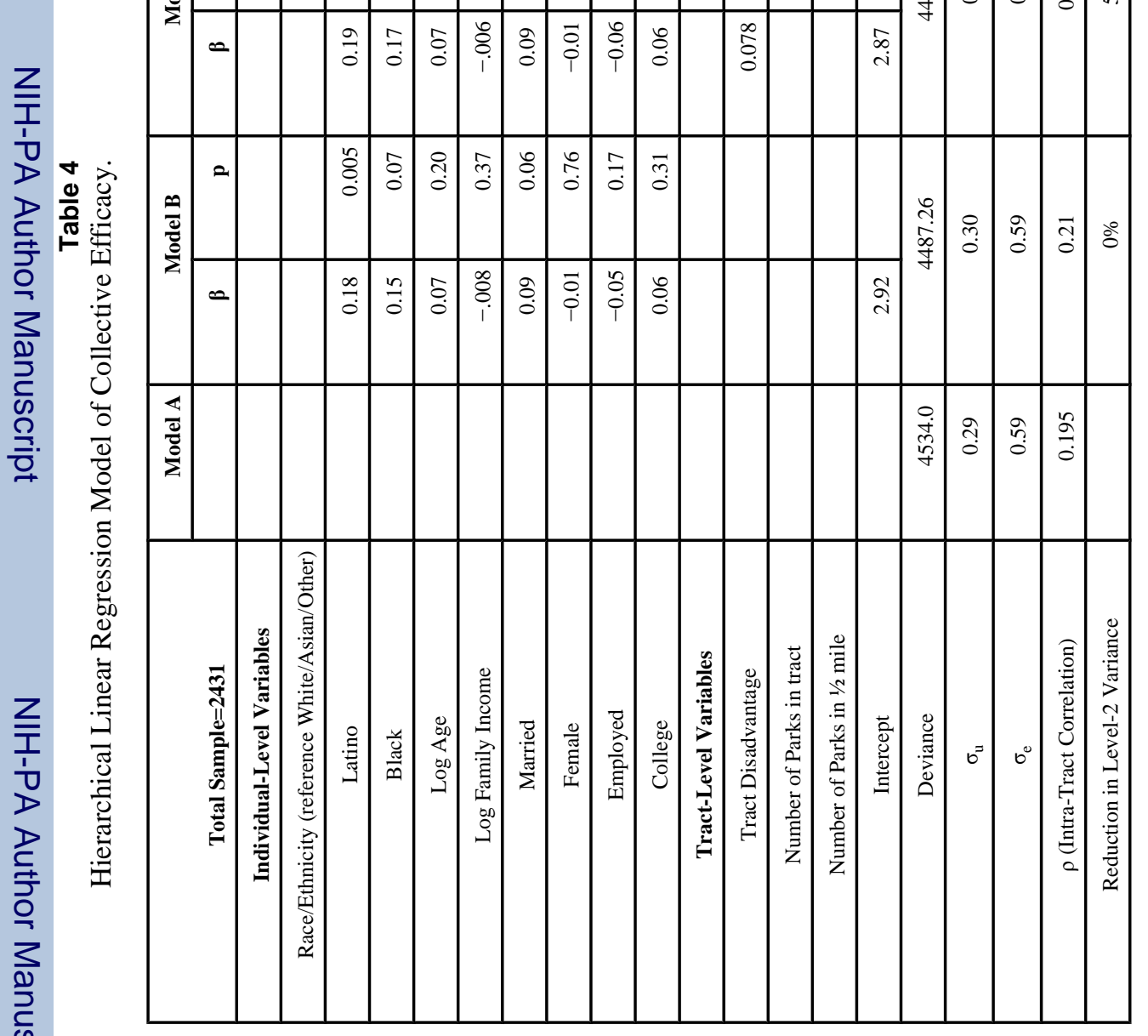

